\title{
High dose intravitreal ganciclovir injection provides a prolonged therapeutic intraocular concentration
}

\author{
N Morlet, S Young, D Naidoo, G Graham, M T Coroneo
}

\begin{abstract}
Background-Although intravitreal high dose ganciclovir has previously been found to provide excellent control of cytomegalovirus (CMV) retinitis, little was known about the vitreous concentrations of ganciclovir after a 2 mg intravitreal injection.

Methods-Eleven vitreous samples were taken from seven patients with CMV retinitis at 24 and 72 hours after a $2 \mathrm{mg}$ intravitreal injection of ganciclovir and the concentration of ganciclovir was measured by high performance liquid chromatography.

Results-The mean concentration of ganciclovir at 24 hours was $143.8 \mathrm{mg} / 1$ (95\% confidence interval 97.8-190) and at 72 hours was $23.4 \mathrm{mg} / 1$ (95\% CI $0-49 \cdot 7)$. The half life ranged from 11.9 to $26 \cdot 3$ (mean 18.8) hours in the four patients who had two samples taken. The mean half life calculated from the mean concentrations at 24 and 72 hours was $18 \cdot 3$ hours, so the calculated mean concentration at 7 days was $0.6 \mathrm{mg} /$.

Conclusions-This suggests that it takes about 7 days to eliminate the intravitreal ganciclovir, and that it is not likely to accumulate with weekly injections. The intravitreal concentrations achieved with high dose therapy remained above the ID $_{50}$ for CMV (0.25-1.22 $\left.\mathrm{mg} / \mathrm{l}\right)$ for up to 7 days.

(Br f Ophthalmol 1996; 80: 214-216)
\end{abstract}

Department of

Ophthalmology,

Prince of Wales

Hospital, University of

New South Wales

N Morlet

$S$ Young

M T Coroneo

Department of Clinical Chemistry, Prince of

Wales Hospital,

University of New

South Wales

D Naidoo

Department of

Physiology and

Pharmacology, School

of Medicine,

University of New

South Wales

G Graham

Correspondence to:

Nigel Morlet, Moorfields Eye Hospital, City Road, London ECiV 2PD

Accepted for publication

9 November 1995

Ganciclovir is the commonest treatment for cytomegalovirus (CMV) retinitis, ${ }^{1}$ but because it is only virostatic, maintenance therapy is required to prevent relapse of the infection. Most physicians administer the drug intravenously; however, up to $20 \%$ of infections do not resolve with induction therapy, ${ }^{2}$ and many patients relapse at a median time of about 8 weeks while on maintenance therapy. ${ }^{3-6}$ Some believe that systemic maintenance therapy is associated with eventual relapse in all patients. ${ }^{34} 7$

Intravitreal therapy has the advantage of delivering the drug directly to the posterior segment of the eye, avoiding systemic side effects. ${ }^{8-10}$ Using high dose intravitreal ganciclovir $(2 \mathrm{mg} / 0 \cdot 1 \mathrm{ml})^{11-14}$ we successfully suppressed the retinitis in 35 eyes of 22 patients. We found that only two patients relapsed on maintenance therapy of weekly injections, at 25 and 42 weeks respectively. ${ }^{13}$
Effective and ongoing control of CMV retinitis by high dose intravitreal ganciclovir injections may reduce the incidence of blinding complications. However, there is a paucity of data about the intraocular pharmacokinetics of ganciclovir. Only one other study estimated the half life to be 13.5 hours from just two vitreous samples after intravitreal ganciclovir injection of $200 \mu \mathrm{g} / 0 \cdot 1 \mathrm{ml} .{ }^{15} \mathrm{In}$ this study, we demonstrated that high dose therapy provides at least 7 days of virostatic levels of ganciclovir in the human eye.

\section{Methods}

Eleven samples of vitreous humour were taken from seven male patients after informed consent, 24 and 72 hours after an intravitreal ganciclovir $(2 \mathrm{mg} / 0.1 \mathrm{ml})$ injection for CMV retinitis. ${ }^{1617}$ The eye was anaesthetised by peribulbar block and decompressed with a mercury bag $(30 \mathrm{~mm} \mathrm{Hg})$ for 15 minutes. Using a 23 gauge needle via the temporal pars plana, $0 \cdot 1-0 \cdot 2 \mathrm{ml}$ of liquid vitreous was aspirated. The samples were then stored frozen at $-8^{\circ} \mathrm{C}$ until analysed by high performance liquid chromatography (HPLC).

HPLC analysis was performed after equal volumes $(100 \mu \mathrm{l})$ of vitreous fluid and $0.8 \mathrm{M}$ perchloric acid were mixed, vortexed, and centrifuged at $10000 \mathrm{~g}$ for 2 minutes. A $10 \mu \mathrm{l}$ aliquot of the supernatant was then injected into a $4.6 \mathrm{~mm}$ octadecyl silica column (Ultrasphere), using an ultraviolet detector set at $254 \mathrm{~nm}$, and a peak integrator. The elution buffer used was $20 \mathrm{mM}$ ammonia acetate and $1 \cdot 2 \%$ acetic acid at a flow rate of $1.5 \mathrm{ml} / \mathrm{min}$.

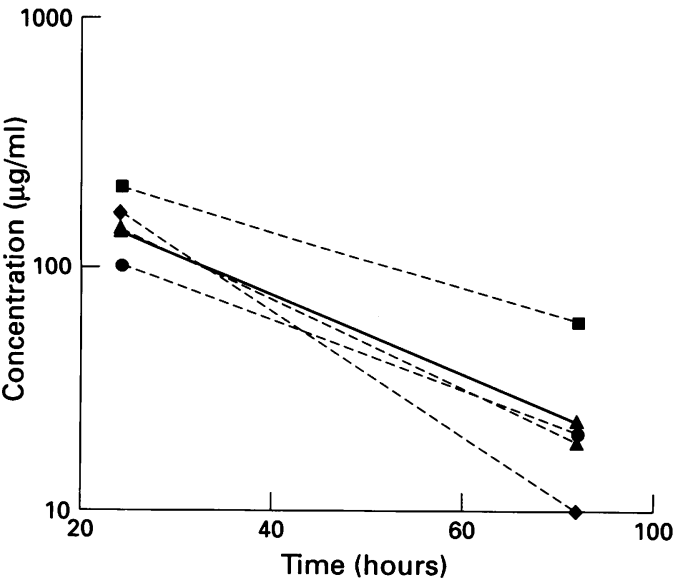

Figure 1 Intravitreal concentration at 24 and 72 hours after intravitreal injection of $2 \mathrm{mg}$ ganciclovir for four patients, and the mean of 11 concentrations from seven patients (bold line). 
Table 1 Intravitreal concentration of ganciclovir $(\mathrm{mg} / \mathrm{l})$ after an intravitreal injection of $2 \mathrm{mg} / 0 \cdot 1 \mathrm{ml} 24$ or 72 hours earlier in seven patients receiving treatment for cytomegalovirus retinitis

\begin{tabular}{|c|c|c|c|c|}
\hline \multirow[b]{2}{*}{ Patient } & \multicolumn{2}{|c|}{ Concentration at } & \multirow{2}{*}{$\begin{array}{l}t_{1 / 2} \\
\text { (hours) }\end{array}$} & \multirow{2}{*}{$\begin{array}{l}\text { Estimated } \\
\text { concentration } \\
\text { at } 7 \text { days }\end{array}$} \\
\hline & 24 hours & 72 hours & & \\
\hline 1 & $212 \cdot 0$ & $59 \cdot 8$ & $26 \cdot 3$ & $4 \cdot 8$ \\
\hline $\begin{array}{l}2 \\
3\end{array}$ & $\begin{array}{l}165 \cdot 4 \\
138 \cdot 2\end{array}$ & $10 \cdot 0$ & $11 \cdot 9$ & 0.04 \\
\hline 4 & $102 \cdot 2$ & $20 \cdot 8$ & $20 \cdot 9$ & 0.9 \\
\hline 5 & 152.8 & $19 \cdot 4$ & $16 \cdot 1$ & 0.3 \\
\hline 6 & - & 6.8 & - & - \\
\hline 7 & $92 \cdot 2$ & - & - & - \\
\hline Mean & 143.8 & $23 \cdot 4$ & $18 \cdot 3^{\star}$ & $0 \cdot 6^{\star}$ \\
\hline
\end{tabular}

*Calculated from mean concentrations at 24 and 72 hours.

The ganciclovir peak eluted at 9 minutes. Quantitation of ganciclovir levels was done by peak area comparison using a set of five prepared calibrators covering the range measured.

The logarithm of the concentrations of ganciclovir in the vitreous humour was plotted against time (Fig 1), and the slope (k) determined by linear regression. The half life of loss of ganciclovir $\left(t_{1 / 2}\right)$ is given by the relation $\mathrm{t}_{1 / 2}=0 \cdot 693 /-\mathrm{k}$.

\section{Results}

The concentrations obtained from the 11 samples are shown in Figure 1 and Table 1. The mean concentration of ganciclovir at 24 hours was $143.8 \mathrm{mg} / \mathrm{l}$ ( $95 \%$ confidence interval $97 \cdot 8-190)$ and at 72 hours $23.4 \mathrm{mg} / 1(95 \% \mathrm{CI}$ $0-49 \cdot 7)$. The half life ranged from 11.9 to $26 \cdot 3$ (mean 18.8) hours in the four patients who had two samples taken. The mean half life calculated from the mean concentrations at 24 and 72 hours was 18.3 hours, so the calculated mean concentration at 7 days was $0.6 \mathrm{mg} / \mathrm{l}$.

\section{Discussion}

This study provides preliminary data on the kinetics of loss of ganciclovir from the vitreous humour in humans. The estimated half life suggests that it takes about 7 days to eliminate ganciclovir after a $2 \mathrm{mg}$ injection, and that ganciclovir is not likely to accumulate with weekly injections. The intravitreal concentration achieved with high dose therapy remained above the inhibitory dose that will inhibit $50 \%$ of activity $\left(\mathrm{ID}_{50}\right)$ for CMV $(0 \cdot 25-1.22 \mathrm{mg} / \mathrm{l}$, Table 2) for up to 7 days. This may account for our observation that rapid resolution of CMV retinitis occurs with twice weekly induction therapy, and there is little relapse with weekly injections.

Although the numbers in our analysis are small, once we established that weekly high dose intravitreal ganciclovir injections were not

Table 2 Antiviral activity of ganciclovir against the herpesvirus family (from Diaz-Llopis et $\mathrm{al}^{24}$ )

\begin{tabular}{ll}
\hline Virus & $I C_{50}(\mathrm{mg} /)$ \\
\hline Herpes simplex 1 & $0 \cdot 05-0 \cdot 18$ \\
Herpes simplex 2 & $0 \cdot 08-0 \cdot 46$ \\
Cytomegalovirus & $0 \cdot 25-1 \cdot 22$ \\
Varicella zoster & $0 \cdot 38-1 \cdot 43$ \\
Epstein-Barr & $0 \cdot 013$ \\
\hline
\end{tabular}

IC $_{50}=$ inhibitory concentration that will inhibit $50 \%$ of activity. likely to accumulate in the vitreous, ethically we could not justify pursuing further samples. Apart from the slight discomfort involved during the procedure, multiple vitreous sampling may slightly increase the risk of retinal detachment in patients with CMV retinitis.

High dose intravitreal ganciclovir therapy may also be a useful treatment for retinochoroiditis caused by other herpesviruses - for example, the acute retinal necrosis syndrome. Table 2 shows the antiviral activity of ganciclovir for all the herpesvirus family. As for $\mathrm{CMV}$, high dose intravitreal ganciclovir would provide up to 7 days of intraocular antiviral activity.

Intravenous administration of ganciclovir achieves a mean inhibitory concentration for CMV in the vitreous for only 8 hours after injection. ${ }^{1819}$ Consequently, maintenance therapy with intravenous treatment does not provide continuous virostatic cover, so it is not surprising that relapse is common. ${ }^{7}$

Inadequate suppression of virus activity was shown to be a major risk factor in the development of retinal detachment which may occur in up to $25 \%$ of patients with CMV retinitis. ${ }^{20}$ A subtherapeutic intraocular concentration of ganciclovir was found in a number of patients with CMV retinitis who had retinal detachment surgery. ${ }^{21}$ Apart from early detection of the retinitis, achieving resolution and preventing relapse with high dose intravitreal ganciclovir may reduce the incidence of retinal detachment. Furthermore, the high peak levels of ganciclovir in the first 48 hours after intravitreal injection may avoid resistance to ganciclovir reported to occur in $16 \%$ of patients. ${ }^{1822}$

We did not observe any toxicity from the high dose ganciclovir. Despite a report that high dose intravitreal ganciclovir resulted in flattening of the electroretinogram (ERG) in pigmented rabbits, ${ }^{23}$ our study of multiple high dose injections in white rabbit eyes found no ERG or histopathological evidence of toxicity ${ }^{15}$ which confirms the findings of DiazLlopez et al. ${ }^{24}$ Smith et al found no evidence of toxicity in rabbit eyes after intraocular implantation of a $6 \mathrm{mg}$ solid pellet of sustained release ganciclovir. ${ }^{25}$

High dose intravitreal ganciclovir is an inexpensive and readily available treatment modality ${ }^{26}$ and achieves prolonged therapeutic levels in the vitreous humour with weekly maintenance therapy for effective control of CMV retinitis.

The authors have no proprietary interest in the materials or methods described in this paper.

1 Palestine AG, Polis MA, De Smet MD, Baird BF, Falloon $\mathrm{J}$, Kovacs JA, et al. A randomized, controlled trial in the treatment of cytomegalovirus retinitis in patients with treatment of cytomegalovirus retinitis

2 Henderly DE, Freeman WR, Causey DM, Rao NA. Cytomegalovirus retinitis and response to therapy with ganciclovir. Ophthalmology 1987; 94: 425-34.

3 Holland GN, Sidikaro Y, Kreiger AE, Hardy D, Sakamoto MJ, Frenkel LM, et al. Treatment of cytomegalovirus retinopathy with ganciclovir. Ophthalmology 1987; 94: 815.

4 Jabs DA, Enger C, Bartlett JG. Cytomegalovirus and acquired immunodeficiency syndrome. Arch Ophthalmol 1989; 107: 75-80.

5 Holland GN, Buhles WC, Mastre B, Kaplan HJ, the UCLA CMV Retinopathy Study Group. A controlled retrospective study of ganciclovir treatment for cytomegalovirus 
retinopathy: use of a standard system for the assessment of disease outcome. Arch Ophthalmol 1989; 107: 1759-66. 6 Studies of Ocular Complications of AIDS Research Group, in collaboration with the AIDS Clinical Trials Group. Mortality in patients with the acquired immunodeficiency syndrome treated with either foscarnet or ganciclovir for cytomegalovirus retinitis. $N$ Engl f Med 1992; 326: 213 .

7 Gross JG, Bozzette SA, Matthews WC, Spector SA, Abramson IS, McCutchan JA, et al. Longitudinal study of cytomegalovirus retinitis in acquired immunodeficiency syndrome. Ophthalmology 1990; 97: 681-6.

8 Ussery FM, Gibson SR, Conklin RI, Piot DF, Stool EW, Conklin AJ. Intravitreal ganciclovir in the treatment of AIDS-associated cytomegalovirus retinitis. Ophthalmology 1988; 95: 640 .

9 Cantrill HL, Henry K, Melroe NH, Knobloch WH, Ramsay RC, Balfour HH. Treatment of cytomegalovirus retinitis with intravitreal ganciclovir: long-term results. with intravitreal ganciclo

10 Heinemann M-H. Long-term intravitreal ganciclovir therapy for cytomegalovirus retinopathy. Arch Ophthalmol 1989; 107: 1767.

11 Heery S, Hollows FC. High dose intravitreal ganciclovir for cytomegalovirus (CMV) retinitis. Aust NZ f Ophthalmol 1989; 17: 405.

12 Young SH, Morlet N, Heery S, Hollows FC, Coroneo MT. High dose intravitreal ganciclovir in the treatment of High dose intravitreal ganciclovir in the treatment of
cytomegalovirus retinitis. Med $f$ Aust 1992; 157: 370-3.

13 Young SH, Morlet N, Graham G, Naidoo D, Coroneo MTC. Improved treatment of CMV retinitis using highdose intravitreal ganciclovir with prolonged intravitreal concentrations. Invest Ophthalmol Vis Sci 1995; 36: S323 (1506).

14 Young SH, Morlet N, Besen G, Wiley CA, Freeman WR, Jones $\mathrm{P}$, et al. Improved treatment of cytomegalovirus retinitis in acquired immune deficiency syndrome with high-dose intravitreal ganciclovir. (in press).

15 Henry K, Cantrill H, Fletcher C, Chinnock BJ, Balfour HH. Use of intravitreal ganciclovir for cytomegalovirus retinitis in a patient with AIDS. Am $\mathcal{F}$ Ophthalmol 1987; 103: 17-23.
16 Morlet N, Young SH, Strachan D, Coroneo MT. Technique of intravitreal injection. Aust NZ $\mathcal{f}$ Ophthalmol 1993; 21: 130-1

17 Morlet N, Young SH. Reduction of pressure rise due to intravitreal injection. Br f Ophthalmol 1993; 77: 572-3.

18 Daikos GL, Pulido J, Kathpalia SB, Jackson GG. Intravenous and intraocular ganciclovir for CMV retinitis in patients with AIDS or chemotherapeutic immunosuppression. Br $\mathcal{F}$ Ophthalmol 1988; 72: 521-4.

19 Schulman J, Peyman GA, Horton MB, Liu J, Barber JC, Fiscella $R$, et al. Intraocular penetration of a new antiviral Fiscella R, et al. Intraocular pentration of a new antiviral 1986; 30: 116-24.

20 Freeman WR, Friedberg DN, Berry C, Quiceno JI, Behette M, Fullerton SC, et al. Risk factors for the development of rhegmatogenous retinal detachment in patients with cytomegalovirus retinitis. Am $\mathcal{f}$ Ophthalmol 1993; 116: 713-20.

21 Kupperman BD, Quiceno I, Flores-Aguilar M, Connor JD, Capparelli EV, Sherwood $\mathrm{CH}$, et al. Intravitreal ganciclovir concentration after intravenous administration in
AIDS patients with cytomegalovirus retinitis: implications for therapy. F Infect Dis 1993; 168: 1506-9.

22 Kuppermann BD, Flores-Aguilar M, Quiceno JI, Rickman LS, Freeman WR. Combination ganciclovir and foscarnet in the treatment of clinically resistant CMV retinitis in patients with AIDS. Arch Ophthalmol 1993; 111: 1359-66.

23 Yoshizumi MO, Lee D, Vinci V, Fajardo S. Ocular toxicity of multiple intravitreal DHPG injections. Graefes Arch Clin Exp Ophthalmol 1990; 228: 350-5.

24 Diaz-Llopis M, Martos MJ, Espana E, Cervera M, Vila AO, Navea A, et al. Liposomally-entrapped ganciclovir for the treatment of cytomegalovirus retinitis in AIDS patients. Doc Ophthalmol 1992; 82: 297-305.

25 Smith TJ, Pearson A, Blandford DL, Brown JD, Goins KA, Hollins JL, et al. Intravitreal sustained-release ganciclovir. Arch Ophthalmol 1992; 110: 255-8.

26 Morlet N, Young SH, Naidoo D, Fong T, Coroneo MT. High dose intravitreal ganciclovir for CMV retinitis: a shelf life and cost comparison study. $\mathrm{Br} \mathcal{F}$ Ophthalmol 1995; 79: 753-5. 